\title{
Newly Synthesized Punicalin and Punicalagin Nano-Prototypes Induce Breast Cancer Cytotoxicity Through ROS-Mediated Apoptosis
}

\author{
Ahmed A Abd-Rabou*, Aziza B Shalby, Soheir E Kotob
}

\begin{abstract}
Objective: Globally, breast cancer represents serious cause of morbidity and mortality. Our goal is to improve nutraceuticals that have the ability to overlap the side effects of conventional therapies and promising tumoricidal effects by using nanotechnology techniques. The current work was premeditated to explore the apoptotic effects of punicalin (PN) and punicalagin (PNG) nano-prototypes, derived from Punica granatum, on human breast cancerous MCF7 and MDA-MB-231 cells in vitro. Methods: Firstly, we prepared and characterized of PN, PGN, and 5-flurouracil (FU)loaded PLGA, PLGA-coated-CS, and PLGA-coated-CS-PEG nano-prototypes. Then, we studied the toxicological and biochemical effects of all nanoformulations. Finally, we measured the genetic and protein expression levels of apoptotic and survival candidates in cancer cells. Results: Our results showed that the newly synthesized nano-prototypes had cytotoxic and apoptotic effects on MCF7 and MDA-MB-231 cell lines. Moreover, they up-regulated Bax and Cas-3 expression levels, as well as down-regulated BCL-2, NF-KB and PI3k expression levels compared to control. Nitric oxide $(\mathrm{NO})$ and zinc $(\mathrm{Zn})$ levels were significantly elevated $(\mathrm{P}<0.05)$ after the application of PN and PNG nanoprototypes compared to the control. Conclusion: PN and PNG nano-prototypes of PLGA decorated with CS and PEG enhanced the anti-cancer activity through induction of cytotoxicity, reactive oxygen species (ROS)-mediated apoptosis.
\end{abstract}

Keywords: Breast cancer cell lines- punicalagin- punicalin- PLGA nanoparticles

Asian Pac J Cancer Prev, 23 (1), 363-376

\section{Introduction}

Universally, cancer is a leading cause of premature mortality among humans (Miller et al., 2020). The cancer incidence expected to rise $70 \%$ by 2030 in low and moderate income countries (Das et al., 2019). In Egypt, as a moderate-income country, breast cancer (BC) is the most common cancer type in women (Abdelaziz et al., 2021). Breast carcinogenesis is defined by a lack of self-regulation in cell division and death, which is a multi-step process. Cancer cells acquire a variety of genotypic and phenotypic characteristics that enable them to survive (Padinjarathil et al., 2018). Modulations of oncogenic transcription candidates are linked with control of apoptosis and cell proliferation (Yang et al., 2020). NF- $\kappa \mathrm{B}$ and PI3k are proteins that are conserved and regulated specific genes targets, such as apoptotic candidates (Vishnoi et al., 2020).

Nutraceuticals have the ability to modulate DNA transcription and control DNA damaging agents in cancer cells. Nutraceuticals such as punicalin (PN) and punicalagin $(\mathrm{PNG})$, that target oncogenic transcription factors, have risen as promising therapeutic agents (Sahm et al., 2020).

The nutraceutical-loaded nano-prototypes speedily interact with cancer cells and introduce promising anticancer candidates (Shende and Mallick, 2020). Ellagitannins (ETs), such as punicalagin (PGN) (Gosset-Erard et al., 2021), isolated from Punica granatum, were stated to have anti-proliferative features by modulating many signaling trails (Naeem et al., 2020). PGN, the largest ET, is hydrolyzed into punicalin (PN), gallic acid, and ellagic acid (Seeram et al., 2005).

ETs have the ability to stop cell growth, cause apoptosis, and block transcription factors that promote cell proliferation. In addition, it was found to decrease cell viability and induce apoptosis through activation of caspase-3 (Silacci P and Tretola, 2019), down-regulate BCL-2 gene, and up-regulate Bax gene (Gupta et al., 2019). These results said that ETs persuaded the apoptosis of cancer cells throughout the mitochondrial pathway (Berköz and Krośniak, 2020).

There are reported disadvantageous of ETs, however they offer defense against several cancer cell types 
(Abd-Rabou et al., 2012; Ahmed et al., 2015). The disadvantageous include humble absorption and low bioavailability in addition to short retention time. ETs, for example, cannot travel through the human body but are hydrolyzed to their moieties in the gastrointestinal system (Macierzyński et al., 2020). To solve these noticed disadvantageous, loading these ETs inside biodegradable and biocompatible nanoparticles may be incorporated. Cancer nanotechnology methods were primarily applied to increase bioavailability and decrease the hydrolysis process of PNG (De Miguel et al., 2016). These nano-strategies using dietary phytochemicals are being subjugated in cancer inhibition (Abd-Rabou et al., 2012, Ahmed et al., 2015).

There is a worldwide interest in nanotechnology and its potential applications in cancer therapy using drug delivery (Lombardo et al., 2019). The nano-size effect gives PLGA-CS-PEG, a poly D-L-lactide-co-glycolide (PLGA) adorned with chitosan (CS) and polyethylene glycol (PEG), unusual physicochemical properties (Abd-Rabou et al., 2017). Many nutraceuticals are delivered to the site of interest using nanoparticles made from the FDA-approved biodegradable polymer PLGA. However, attaining successful drug targeting with PLGA nano-formulation requires fast opsonization by phagocytes (Rai et al., 2019). To reduce phagocytic effects and increase the lifespan of the nanoparticles, surface coating with biocompatible polymers, such as CS and PEG, was utilized (Shalby et al., 2017). Intriguingly, the chemical modification of CS with PEG increases biocompatibility, while reducing circulating plasma protein adsorption on the material surface (Lombardo et al., 2019). Consequently, a novel approach of nano-drug encapsulation to enrich the efficacy of bioactive Punica granatum agents (Khan et al., 2021).

The purposes of this work were represented in: (1) encapsulation of PN and PNG in three consequent nano-prototypes of PLGA, PLGA-coated-CS, and PLGA-coated-CS-PEG nano-prototypes in order to surge their anti-cancer activities via increasing uptake capacity of the drug. (2) studying the cytotoxicity and apoptosis of these nano-prototypes versus breast cancerous MCF7 and MDA-MB-231 cells.

\section{Materials and Methods}

\section{Materials}

Punicalin (PN, Cat. No. 67988) and punicalagin (PNG, Cat. No. P0023), 5-Flurouracil (FU, Cat. No. F6627), chitosan (CS, Cat.No. 448869), Poly (D, L-lactide-coglycolide) (PLGA, Cat. No. P2191), polyethylene glycol (PEG, Cat. No. 1546445), and 3-(4,5-dimethylthiazol2-yl)-2,5-diphenyltetrazolium bromide (MTT) were purchased from (Sigma-Aldrich Co., St. Louis, MO). BCL-2, Bax, Cas3, NF-k $\beta$ and PI3k were measured quantitavely using ELISA kits (Wuhan Fine Biotech, China). Glucose, Nitric oxide (NO), Malondialdehyde (MDA), and Zinc (Zn) detection kits were purchased from (Spectrum Diagnostics, Egypt). RNeasy mini kit was purchased from (Qiagen, Germany). cDNA synthesis kit was purchased from (Intron biotechnology, Korea).
SYBR Premix was purchased from (Thermo fisher scientific, USA). Annexin V and propidium iodide kit were purchased from (ThermoFisher Scientific, UK). Ultrapure water (Millipore, Bedford, MA, USA) was used. All other chemicals were of analytical grade unless where otherwise stated.

\section{Nano-prototypes \\ Preparation of PLGA nano-prototype}

PLGA nanoparticles were prepared by oil-in-water (O/W) single emulsion solvent evaporation method (Parveen and Sahoo, 2011) with slight modifications. Briefly, $100 \mathrm{mg}$ of PLGA polymer were dissolved in 3 $\mathrm{ml}$ of organic solvent (chloroform) to form a primary emulsion which was further emulsified in an aqueous PVA solution $(12 \mathrm{ml}, 2 \% \mathrm{w} / \mathrm{v})$ to form an oil-in-water emulsion using a microtip probe sonicator (VC 505, Vibracell Sonics, Newton, USA) set at $55 \mathrm{~W}$ of energy output for 2 min over an ice bath. The emulsion was stirred overnight for the evaporation of the organic solvent. Excess amount of PVA was removed next day by ultracentrifugation at 50, $602 \mathrm{xg}$ at $40 \mathrm{C}$ for $20 \mathrm{~min}$ (SorvallUltraspeed Centrifuge, Kendro, USA) followed by washing thrice with double distilled water.

\section{Surface decoration of PLGA nano-prototype with CS and $P E G$}

For the preparation of chitosan coated PLGA nanoparticles, a similar protocol was followed as mentioned earlier (preparation of PLGA nanoparticles), with slight modifications. Chitosan solution $(12 \% \mathrm{w} / \mathrm{w})$ was prepared in $1 \%$ glacial acetic acid, filtered and then added to the aqueous PVA solution prior to emulsification with the polymer to get chitosan coated PLGA(PLGA-CS) nanoparticles. Similarly, to study the effect of PEG, 5\% w/w, molecular weight $(2 \mathrm{kD})$ of PEG was added to the aqueous PVA and chitosan solution before emulsification to get PEG coated (PLGA-CS-PEG) nanoparticles (Parveen and Sahoo, 2011).

\section{Filtration and dialysis}

For therapeutic applications, PN, PNG and FU were loaded in PLGA, PLGA-CS, and PLGA-CS-PEG nano-prototypes using the similar approach as mentioned before, by adding these drugs to the mixture prior emulsification, with a certain calculated concentration, then they were named "the total dosage of the drug".

Each nano-formulations was divided into 3 portions; (1) one to confirm "the total dosage of the drug", which equals the free- plus nano-conjugated drug using UV spectrometer detection, (2) the second portion for measuring the free concentrations of the drug by eluting it through a column of regenerated cellulose (Amicon 10,000 MWCO ultra filter, Millipore, Schwalbach, D), and (3) the third portion for measuring the concentrations of the nano-conjugated drug by performing dialysis tubing for eliminating the impurities and the free drug.

\section{Characterization of the nanoparticles \\ Calibration curve and entrapment efficiency measurements} Calibration curves were generated for PN, PNG and 
FU using serial dilutions for each drug. For PN: 0.0515, $0.103,0.206,0.825$ and $1.65 \mathrm{mg} / \mathrm{mL}$. For PGN: 0.0103, $0.0206,0.0412,0.0825,0.165$ and $0.3 \mathrm{mg} / \mathrm{mL}$. For FU: $0.039,0.078,0.156,0.3125,0.625$ and $1.25 \mathrm{mg} / \mathrm{mL}$. All data were equipped and processed with the microplate reader (BMG Labtech, Germany). The drug entrapment efficiency was calculated from the ratio of the drug amount incorporated into the nanoparticles to the total added drug amount.

\section{Particle size and zeta potential analyses}

Mean particle size and zeta potential of the nanoparticles were determined by photon correlation spectroscopy (PCS) using a Zeta Sizer (Nano ZS, Malvern Instruments, UK), All the samples were maintained at a constant temperature of $25.0^{\circ} \mathrm{C}$ and all experiments and each batch were analyzed in triplicates.

\section{Transmission electron microscopic (TEM)}

Particle morphology and size of all nanoparticles were examined by transmission electron microscopy (TEM, Philips CM-10, FEI Inc., Hillsboro, OR, USA). 100 g/ $\mathrm{ml}$ nano-suspensions were dropped into Formvar-coated copper grids, and after complete drying, the samples were stained using 2\% w/v uranyl acetate (Electron Microscopy Services, Ft. Washington, PA). Image capture and analysis were done using Digital Micrograph and Soft Imaging Viewer Software

\section{In-vitro studies}

\section{Cancer cell propagation and maintenance}

Human sensitive and resistant cell lines were purchased from VASCERA Co. (Vaccines Sera and Drugs) which were obtained from American Type Culture Collection (ATCC, USA); human breast cancer cell lines MCF7 (Cat. No.HTB-22TM) and MDA-MB-231 (Cat. No. HTB-26 $\left.{ }^{\mathrm{TM}}\right)$. Breast cells were cultured using Dulbecco's modified Eagle's medium (DMEM) and Roswell Park Memorial Institute (RPMI-1640) medium. All media were supplemented with $4.5 \mathrm{~g} / \mathrm{L}$ Glucose with L-Glutamine and $10 \%$ fetal bovine serum (FBS). The cells were incubated in $5 \% \mathrm{CO}_{2}$ humidified at $37^{\circ} \mathrm{C}$ for growth maintenance.

\section{Measurement of cytotoxicity}

All prototypes were evaluated by MTT assay (Van Meerloo et al., 2011) using MCF7 and MDA-MB-231 cells. Briefly, the cells were cultured in 96-well plates at a density of $1 \times 104$ cells/well. All prototypes with their proposed concentrations $(0,25,50,75$ and 100 $\mu \mathrm{M})$ were added in the media of these cell lines. Culture media with nano-void (i.e. nano-capsule without loaded drug) was used as control for the drug-loaded nano-formulations and their free counterparts. After 24 $\mathrm{h}$ incubation, MTT dissolved in PBS was added to each well at a final concentration of $5 \mathrm{mg} / \mathrm{ml}$, and the samples were incubated at $37^{\circ} \mathrm{C}$ for $4 \mathrm{~h}$. Water-insoluble dark blue formazan crystals, that formed during MTT cleavage in actively metabolizing cells, were dissolved in dimethyl sulfoxide (DMSO). Absorbance was measured at 455 $\mathrm{nm}$, using a microplate reader (BMG Labtech, Germany). The cell viability (\%) was calculated and compared with the controls.

\section{The half inhibitory concentration and fold change}

The half maximal inhibitory concentrations $\left(\mathrm{IC}_{50}\right)$ values, the concentrations inhibit $50 \%$ of cell viabilities, were calculated by plotting the percentages of cell viabilities versus the concentrations of the sample using polynomial concentration-response curve fitting models (OriginPro 8 software). Finally, the fold changes of nanoformulations versus their free counterparts were measured in MCF7 and MDA-MB-231 cell lines.

\section{Apoptosis using flow cytometry}

Annexin V and propidium iodide (PI) stains were used in determination of apoptosis after treatment with the free and nano-prototypes of PN and PNG post $24 \mathrm{~h}$ of their incubation over cells. The apoptotic analysis was dedicated to differentiate between early and late apoptotic cells, as well as necrotic cells. The apoptosis of the treated and untreated MCF7 and MDA-MB-231 cell lines with the proposed $\mathrm{PN}$ and PNG prototypes was analyzed by flow cytometer apparatus (Beckman Coulter, USA).

\section{Biochemical studies \\ Glucose uptake measurement}

Glucose consumption rate of MCF7 and MDA-MB-231 cells were measured upon different nano-prototypes and their free counterparts using glucose detection kit (Spectrum Diagnostics, Egypt). Briefly, the cells were cultured in 96 -well plates at a density of $1 \times 10^{4}$ cells/ well. After 24 h, $5 \mathrm{mM}$ of glucose and different free and nano- prototypes were added in the media after $2 \mathrm{hr}$ of cells starvation. $\mathrm{IC}_{50}$ dosages of all prototypes were used in this experiment. Absorbance was measured at A450 nm using the microplate reader (BMG Labtech, Germany) after 10 min incubation with the glucose detector. The delta change of glucose consumption rate in $\mathrm{mmol} / \mathrm{L}$ was calculated and compared with the untreated and nano-void controls.

\section{Measurements of oxidative stress candidates}

Nitric oxide (NO), Malondialdehyde (MDA), and Zinc (Zn) levels released from MCF7 and MDA-MB-231 cells were measured using colorimetric kits purchased from (Spectrum Diagnostics, Egypt). Briefly, these cells were cultured in 96-well plates at a density of $1 \times 10^{4}$ cells/ well. After $24 \mathrm{~h}$, different free and nano-prototypes were added in the media. $\mathrm{IC}_{50} \mathrm{~s}$ of the proposed $\mathrm{PN}$ and $\mathrm{PNG}$ formulations were used in this experiment.

Nitric oxide (NO): NO was hastily oxidized to nitrite and nitrate which were used to quantitate NO production. In NO assay colorimetric kit, Griess reagent was used to converts nitrite to a deep purple azo agent, which reflected nitric oxide amount in the samples. Finally, optical density was measured at A540 $\mathrm{nm}$ using the microplate reader (BMG Labtech, Germany).

Malondialdehyde (MDA): Quantification of lipid peroxidation was essential to assess oxidative stress in pathophysiological processes, where the end product of this process was MDA. Lipid peroxidation colorimetric assay kit was a sensitive detection tool of MDA. The free MDA present in the sample was reacted with thiobarbituric 
acid (TBA) to generate a MDA-TBA adduct, which could be easily quantified colorimetrically at A532 $\mathrm{nm}$ using the microplate reader (BMG Labtech, Germany).

Zinc (Zn): Zn was quantified using a convenient colorimetric assay. Practically, $\mathrm{Zn}$ was bound to a ligand and the colored product was then detected at an absorbance of A560 $\mathrm{nm}$ using the microplate reader (BMG Labtech, Germany).

Genetic expressions of $B C L-2, B A X$, Caspase 3, $N F-\kappa B$, and PI3k using quantitative real time $q R T-P C R$

RNA extraction and cDNA synthesis: Total RNA was extracted from human breast cancerous MCF7 and MDA-MB-231 cells using the RNeasy mini kit (Qiagen, Germany) according to the manufacturer's protocol. The concentration and purity of RNA was identified using a nanodrop UV spectrophotometer (thermo fisher scientific, USA). The cDNA was synthesized using first strand cDNA synthesis kit (Intron biotechnology, Korea) using random hexamer primer and oligo(dt)primers according to the manufacturer's instruction.

Quantitative RT-PCR: Relative expressions of BCL2, Bax, Cas3, NF- $\mathrm{BB}$ and PI3K genes were performed. GAPDH was used as a house keeping gene. QIAGEN's real-time PCR cycler (Rotor-Gene Q, Valencia, CA) was used to determine the cDNA copy number. PCR reactions were set up in $25 \mu \mathrm{L}$ reaction mixtures containing 12.5 $\mu \mathrm{L}$ SYBR Premix (Thermo fisher scientific, USA), $0.5 \mu \mathrm{L}$ $0.2 \mathrm{mM}$ forward primer, $0.5 \mu \mathrm{L} 0.2 \mathrm{mM}$ reverse primer (primer sequence: Table 1), $6.5 \mu \mathrm{L}$ distilled water and 5 $\mu \mathrm{L}$ of cDNA template. Primers were designed through NCBI BLAST gene banking before purchasing from (Thermo fisher scientific, USA) (https://blast.ncbi.nlm. nih.gov/Blast.cgi). The reaction program was allocated to three steps. First step was at $95.0^{\circ} \mathrm{C}$ for $3 \mathrm{~min}$. Second step consisted of 40 cycles in which each cycle divided to three steps: (a) at $95.0^{\circ} \mathrm{C}$ for $15 \mathrm{~s}$; (b) at $55.0-60.0^{\circ} \mathrm{C}$ for $30 \mathrm{~s}$; and (c) at $72.0^{\circ} \mathrm{C}$ for $30 \mathrm{~s}$. The third step was consisted of several cycles, which started at $60.0^{\circ} \mathrm{C}$ and then increased about $0.5^{\circ} \mathrm{C}$ every $10 \mathrm{~s}$ up to $95.0^{\circ} \mathrm{C}$. At the end of each qRT-PCR, a melting curve analysis was performed at $95.0^{\circ} \mathrm{C}$, then $55.0-60.0^{\circ} \mathrm{C}$, then $95.0^{\circ} \mathrm{C}$ to check the quality of the used primers. The triplicate samples were assessed for variability using geometric standard deviations. The geometric mean of the triplicate run for each gene of interest was normalized with the geometric mean of GAPDH.

\section{Protein analysis using ELISA}

Human BCL-2, Bax, Cas3, NF- $\kappa$ B and PI3K proteins were measured quantitavely using ELISA kits according to the manufacturer's instructions and procedures (Wuhan Fine Biotech, China).

\section{Statistical analysis}

All assays were repeated three times $(n=3)$. Comparisons between nano-prototypes and their free counterparts versus controls were made using a two-tailed Student's $\mathrm{t}$ test, and values of $\mathrm{P}<0.05$ were considered statistically significant. SPSS (version 22) and OriginPro (version 8) were used for statistical analysis.

\section{Results}

\section{Entrapment efficiency (EE)}

The calibration curves were plotted for puncalin (PN), punicalagin (PNG), and 5-fluorouracil (FU) to measure their entrapment efficiency (EE) inside the prepared nano-prototypes, as shown in (Figure 1A-C).

Also, the results in (Table 2) showed that the EE\% was approximately ranging from the lowest recorded $\mathrm{EE} \% 55.5 \pm 4.53 \%$ for PNG PLGA-CS to the highest $\mathrm{EE} \% 87.0 \pm 4.09 \%$ for PN PLGA-CS-PEG nanoparticles.

\section{TEM and Malvern Zeta-Sizer}

Characterizations of the prepared nano-prototypes using TEM imaging, size distribution, and zeta potential plots were illustrated in (Figure 2). TEM, size distribution, and zeta potential of PLGA(Figure 2A), PN PLGA(Figure 2B), PNG PLGA (Figure 2C), PLGA-CS (Figure 2D), PN PLGA-CS (Figure 2E), PNG PLGA-CS (Figure 2F), PLGA-CS-PEG (Figure 2G), PN PLGA-CS-PEG (Figure 2H), PNG PLGA-CS-PEG (Figure 2I), FU PLGA (Figure 2J), FU PLGA-CS (Figure 2K), and FU PLGA-CS-PEG (Figure 2L) nano-prototypes were illustrated as rounded particles containing of core and surrounded nano-capsule.

The size distribution of PLGA nanoparticles was recorded with a peak at $236.3 \mathrm{~nm}$ and polydispersity index (PDI) equal 0.19 using Malvern Zeta-Sizer. It was measured that zeta potential of PLGA nanoparticles equal $0.41 \mathrm{mV}$ as shown in (Fig 2A). Figure 2B illustrates size distribution of PN PLGA nanoparticles with peak at $262.4 \mathrm{~nm}$ and PDI equal 0.077. Moreover, we measured zeta potential of PN PLGA nanoparticles $(1.4 \mathrm{mV})$ as shown in (Figure 2B). Figure 4C shows size distribution of PGN PLGA nanoparticles of around $289.6 \mathrm{~nm}$ and PDI equal 0.32. It was recorded that zeta potential of PGN PLGA nanoparticles equal $1.09 \mathrm{mV}$. Figure 2D illustrates size distribution of PLGA-CS nanoparticles with a peak at $177.1 \mathrm{~nm}$ and PDI equal 0.21. We measured Zeta potential of PLGA-CS nanoparticles $(7.54 \mathrm{mV})$. Figure 2E illustrates size distribution of PN PLGA-CS

Table 1. Primer Sequences for Real Time qRT-PCR.

\begin{tabular}{lcl}
\hline Gene & $\begin{array}{c}\text { Primer } \\
\text { sequence }\end{array}$ \\
\hline BCL-2 & F & 5'-CTGCACCTGACGCCCTTCACC-3' \\
& R & 5'-CACATGACCCCACCGAACTCAAAGA-3' \\
Bax & F & 5'-ATGGCTTCTATGAGGCTGAG-3' \\
& R & 5'-CGGCCCCAGTTGAAGTTG-3' \\
Cas3 & F & 5'-GTGGAACTGACGATGTGGC-3' \\
& R & 5'-CGCAAAGTGACTGGATGAACC-3' \\
NF-k $\beta$ & F & 5'-ATGGCTTCTATGAGGCTGAG-3' \\
& R & 5'-GTTGTTGTTGGTCTGGATGC-3' \\
PI3K & F & 5'-GCTCTCGGTTGATTCCAACGT-3' \\
& R & 5'-ATGGCTTCTATGAGGCTGAG-3' \\
GAPDH & F & 5'-GTCTCCTCTGACTTCAACAGCG-3' \\
& R & 5'-ACCACCCTGTTGCTGTAGCCAA-3' \\
\hline
\end{tabular}

$\mathrm{F}$, forward primer; $\mathrm{R}$, reverse primer 


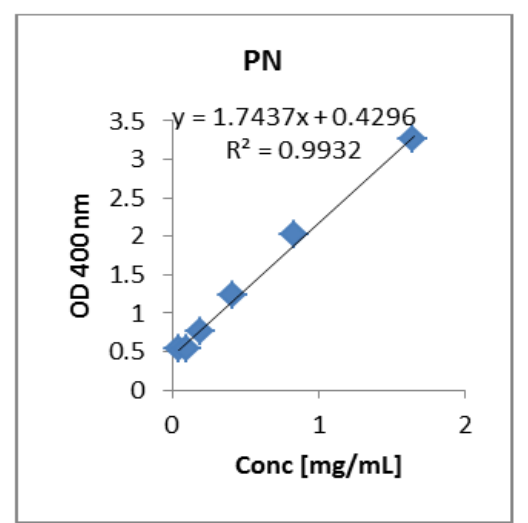

(A)

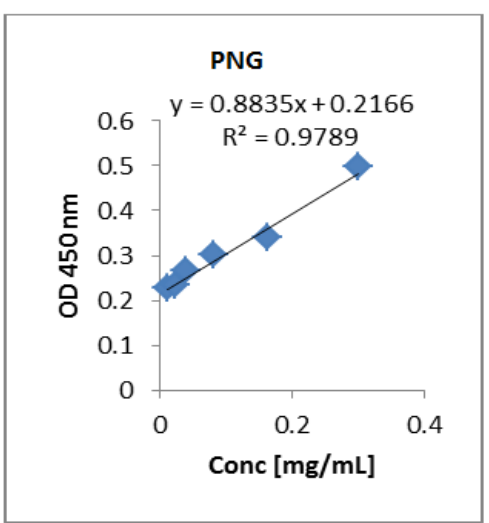

(B)

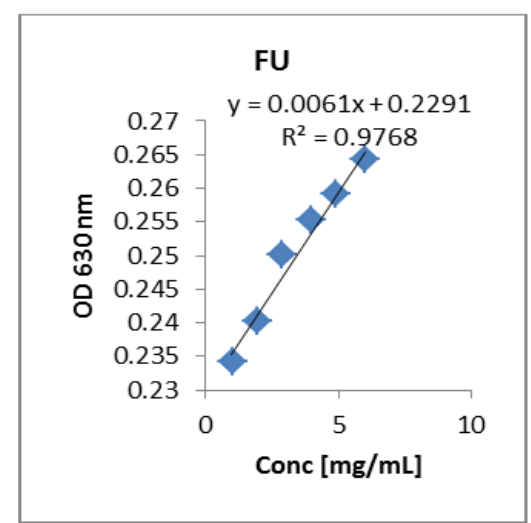

(C)

Figure 1. Calibration Curves of Free (A) Punicalin "PN", (B) Punicalagin "PNG", and (C) 5-fluorouracil "FU". The serial dilutions used for drawing the calibration curves are as follow: For PN: $0.0515,0.103,0.206,0.825$ and 1.65 $\mathrm{mg} / \mathrm{mL}$. For PGN: 0.0103, 0.0206, 0.0412, 0.0825, 0.165 and $0.3 \mathrm{mg} / \mathrm{mL}$. For 5-FU: 0.039, 0.078, 0.156, 0.3125, 0.625 and $1.25 \mathrm{mg} / \mathrm{mL}$.

nanoparticles with a peak at $239.7 \mathrm{~nm}$ and PDI equal 0.099. We measured Zeta potential of PN PLGA-CS nanoparticles $(3.97 \mathrm{mV})$. Figure $2 \mathrm{~F}$ illustrates size distribution of PNG PLGA-CS nanoparticles with a peak at $189 \mathrm{~nm}$ and PDI equal 0.09. It was measured that Zeta potential of PN PLGA-CS nanoparticles equal $8.57 \mathrm{mV}$.
Figure 2G illustrates size distribution of PLGA-CS-PEG nanoparticles with a peak at $250.5 \mathrm{~nm}$ and PDI equal 0.96. We measured Zeta potential of PLGA-CS-PEG nanoparticles equal $8.34 \mathrm{mV}$. Figure $2 \mathrm{H}$ illustrates size distribution of PN PLGA-CS-PEG nanoparticles with a peak at $217.3 \mathrm{~nm}$ and PDI equal 0.079. We measured Zeta

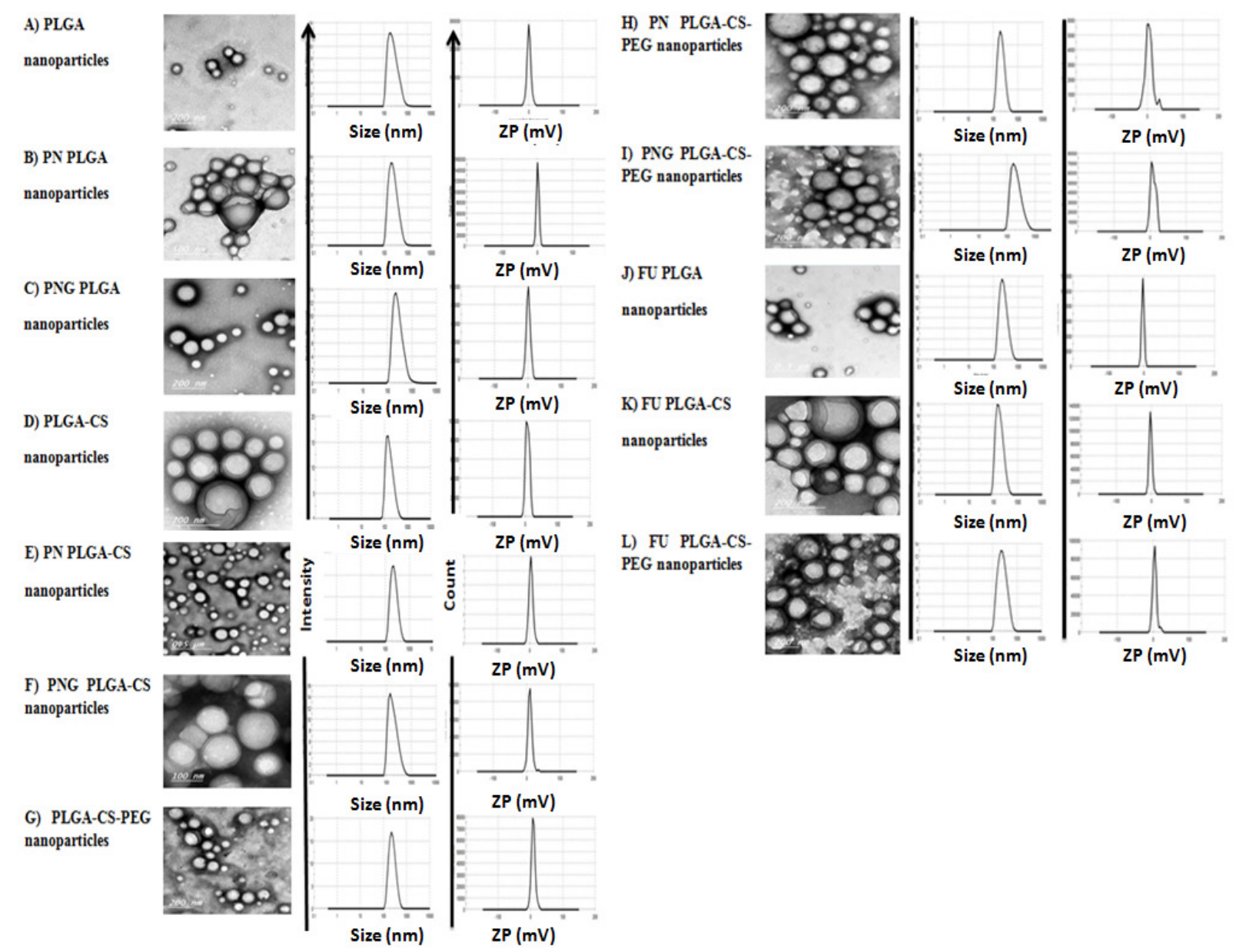

Figure 2. Characterization of the Synthesized Nanoparticles. TEM, size distribution, and zeta potential of PLGA (A), PN PLGA (B), PNG PLGA (C), PLGA-CS (D), PN PLGA-CS (E), PNG PLGA-CS (F), PLGA-CS-PEG (G), PN PLGA-CS-PEG (H), PNG PLGA-CS-PEG (I), FU PLGA (J), FU PLGA-CS (K), and FU PLGA-CS-PEG (L) nanoparticles showing rounded particles containing of core and surrounded capsule. 
Table 2. The Size Distribution, PDI, and Zeta Potential of Each Nano-Prototypes

\begin{tabular}{lcccc}
\hline Nanoformulation & Size & PDI (polydispersity index) & Zeta potential & EE \% \\
\hline PLGA & $236.3 \pm 16.54$ & $0.19 \pm 0.01$ & $0.41 \pm 0.03$ & - \\
PN PLGA & $262.4 \pm 18.37$ & $0.077 \pm 0.01$ & $1.4 \pm 0.10$ & $81.01 \pm 3.67$ \\
PNG PLGA & $289.6 \pm 20.27$ & $0.32 \pm 0.02$ & $0.109 \pm 0.01$ & $84.00 \pm 5.88$ \\
PLGA-CS & $177.1 \pm 12.40$ & $0.21 \pm 0.01$ & $7.54 \pm 0.12$ & - \\
PN PLGA-CS & $239.7 \pm 6.78$ & $0.099 \pm 0.01$ & $3.97 \pm 0.28$ & $79.03 \pm 3.53$ \\
PNG PLGA-CS & $189 \pm 13.23$ & $0.09 \pm 0.01$ & $8.57 \pm 0.60$ & $55.5 \pm 4.53$ \\
PLGA-CS-PEG & $250.5 \pm 7.54$ & $0.96 \pm 0.06$ & $8.34 \pm 0.58$ & - \\
PN PLGA-CS-PEG & $217.3 \pm 5.21$ & $0.079 \pm 0.01$ & $3.47 \pm 0.24$ & $87.0 \pm 4.09$ \\
PNG PLGA-CS-PEG & $226.0 \pm 15.82$ & $0.23 \pm 0.02$ & $8.57 \pm 0.60$ & $82.0 \pm 3.74$ \\
FU PLGA & $266.3 \pm 8.64$ & $0.167 \pm 0.01$ & $-2.62 \pm 0.18$ & $76.5 \pm 2.32$ \\
FU PLGA-CS & $188.8 \pm 13.22$ & $0.107 \pm 0.01$ & $-2.37 \pm 0.17$ & $69.01 \pm 3.83$ \\
FU PLGA-CS-PEG & $270.4 \pm 8.93$ & $0.21 \pm 0.01$ & $3.9 \pm 0.27$ & $70.02 \pm 2.83$ \\
\hline
\end{tabular}

PLGA, PLGA-CS, PLGA-CS-PEG, nano-voids without entrapped drugs; PN, punicalin; PNG, punicalagin; FU, 5-flurouracil; EE, entrapment efficiency; All data represented in mean $\pm \mathrm{SD}$

potential of PN PLGA-CS-PEG nanoparticles (3.47 mV). Figure 2I illustrates size distribution of PNG PLGA-CSPEG nanoparticles with a peak at $226 \mathrm{~nm}$ and PDI equal 0.23 . Zeta potential of PNG PLGA-CS-PEG nanoparticles was $8.57 \mathrm{mV}$. Figure 2J illustrates size distribution of FU PLGA nanoparticles with a peak at $266.3 \mathrm{~nm}, \mathrm{PDI}=0.167$. Zeta potential of FU PLGA nanoparticles was $-2.62 \mathrm{mV}$. Figure $2 \mathrm{~K}$ illustrates size distribution of FU PLGA-CS nanoparticles with a peak at $188.8 \mathrm{~nm}, \mathrm{PDI}=0.107$. Zeta potential of FU PLGA-CS nanoparticles was $-2.37 \mathrm{mV}$. Figure 2L illustrates size distribution of FU PLGA-CSPEG nanoparticles with a peak at $270.4 \mathrm{~nm}, \mathrm{PDI}=0.21$. Finally, we measured Zeta potential of FU PLGA-CS-PEG nanoparticles $(3.9 \mathrm{mV})$.

Three repeated measurments (mean $\pm \mathrm{SD}$ ) of the particle size, PDI, zeta potential, and EE were measured
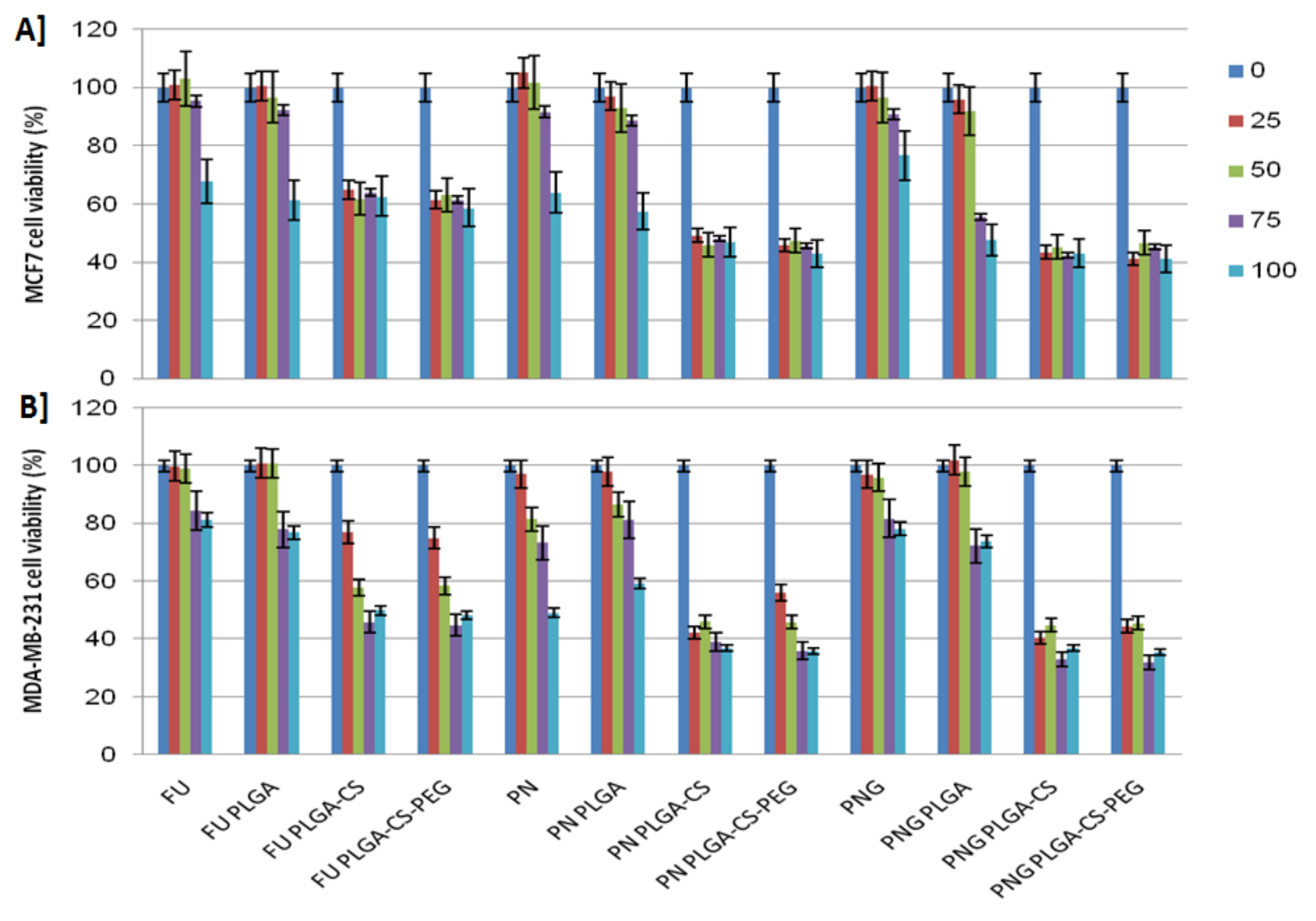

Therapeutic groups

Figure 3. The Cytotoxic-Based Mitochondrial Activity Using MTT Assay. Anti-cancer activities against MCF7 (A) and MDA-MB-231 (B) cell lines upon FU, PN, and PNG free- and nano-prototypes were assessed. Three different experiments $(n=3)$ were done and the incubation time was $24 \mathrm{~h}$. 

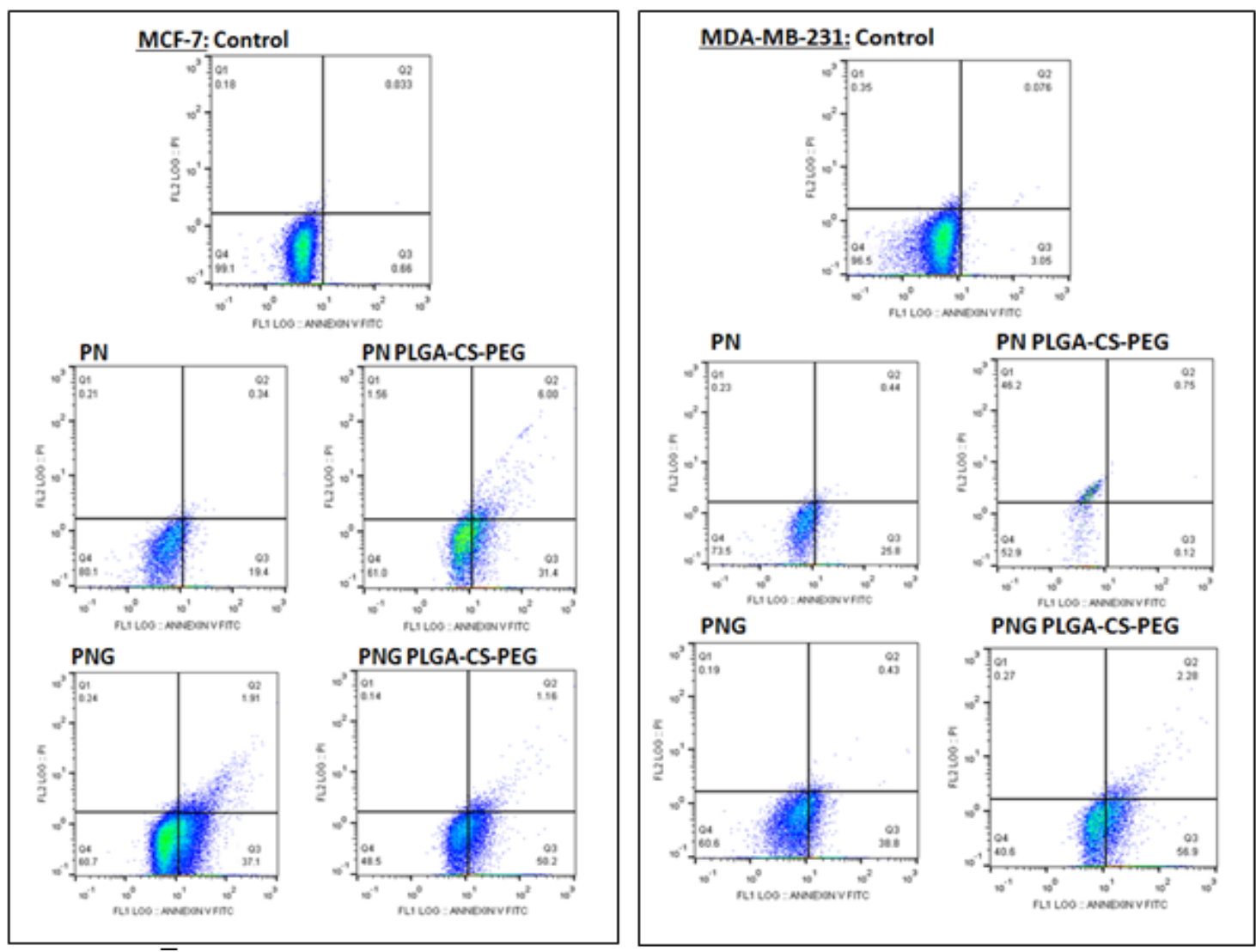

Figure 4. Apoptosis Using Flow Cytometry. Induction of apoptosis in breast cancer MDA-MB-231 (A) and MCF7 (B) cell lines using free and nano PN and PNG prototypes.

for all the tested nanoformulations, as represented in (Table 2). The size of the particles were averaged between $(177.1 \pm 12.40$ and $289.6 \pm 20.27 \mathrm{~nm})$, PDI were between $(0.077 \pm 0.01$ and $0.96 \pm 0.06)$, zeta potential were between $(-2.62 \pm 0.18$ and $+8.57 \pm 0.60 \mathrm{mV})$ and $\mathrm{EE}$ were in-between $(55.5 \pm 4.53 \%$ and $87.0 \pm 4.09 \%)$.

\section{Cytotoxicity of $P N$ and $P N G$ prototypes}

The cytotoxicity of prototypes of $\mathrm{PN}, \mathrm{PNG}$, and FU were examined against human breast cancerous MCF7 and

Table 3. The Cytotoxicity of the Prepared Prototypes on Breast Cancer Cell Lines after 24 hr Incubation.

\begin{tabular}{lcc}
\hline Formulas/ Cell lines & MCF7 cells & MDA-MB-231 cells \\
\hline FU & ND & ND \\
PLGA & ND & ND \\
PLGA-CS & ND & $68.66 \pm 3.43$ \\
PLGA-CS-PEG & ND & $65.97 \pm 3.29$ \\
PN & ND & ND \\
PN PLGA & ND & ND \\
PN PLGA-CS & $38.15 \pm 1.90$ & $33.68 \pm 1.68$ \\
PN PLGA-CS-PEG & $37.11 \pm 1.85$ & $38.91 \pm 1.94$ \\
PNG & ND & ND \\
PNG PLGA & $93.56 \pm 4.67$ & ND \\
PNG PLGA-CS & $33.77 \pm 1.68$ & $30.9 \pm 1.54$ \\
PNG PLGA-CS-PEG & $34.6 \pm 1.73$ & $32.78 \pm 1.63$
\end{tabular}

FU, reference drug for breast cancer cell lines (MCF7; MDA-MB-231); $\mathrm{ND}$, not detectable (more than $100 \mu \mathrm{M}$ ).
MDA-MB-231 cells at consequent dosages $(0,25,50,75$, and $100 \mu \mathrm{M})$ using MTT assay. Data illustrated in Table (3) and (Figure 3 ) showed the \% of breast cancerous cell viabilities post $24 \mathrm{~h}$ of drugs incubation versus untreated cells.

The current findings revealed that PNG-loaded PLGA$\mathrm{CS}\left(\mathrm{IC}_{50}=33.77 \mu \mathrm{M}\right)$ and PNG-loaded PLGA-CS-PEG $\left(\mathrm{IC}_{50}=34.6 \mu \mathrm{M}\right)$ had the lowest recorded $\mathrm{IC}_{50} \mathrm{~s}$ and the highest cytotoxic effects against MCF7 cancer cell line compared to PNG-loaded PLGA $\left(\mathrm{IC}_{50}=93.56 \mu \mathrm{M}\right)$. While, the free PNG had undetectable $\mathrm{IC}_{50}$ (more than $100 \mu \mathrm{M}$ ) against MCF7 and MDA-MB-231 cancer cell lines. Our findings revealed that PN-encapsulated PLGA-coatedCS-PEG $\left(\mathrm{IC}_{50}=37.11 \mu \mathrm{M}\right)$ followed by PN- encapsulated PLGA-coated-CS $\left(\mathrm{IC}_{50}=38.15 \mu \mathrm{M}\right)$ were effective against MCF7 cancer cell line. On the other hand, the PN PLGA NPs and the free drug had undetectable $\mathrm{IC}_{50}$. As a result, we may conclude that CS plus PEG increased PN and PNG's capacity to prevent MCF7 breast cancer proliferation in vitro.

PNG-loaded PLGA-CS, PNG-loaded PLGA-CS-PEG, PN-loaded PLGA-CS and PN-loaded PLGA-CS-PEG $\left(\mathrm{IC}_{50}=30.9 ; 32.78 ; 33.68\right.$ and $38.915 \mu \mathrm{M}$ respectively $)$ had significant cytotoxic effects on MDA-MB-231 breast cancer cell lines in comparison with hat of unloaded PLGA-CS-PEG and PLGA-CS ( $\mathrm{IC}_{50} \mathrm{~s}=65.97 \mu \mathrm{M}$ and $68.66 \mu \mathrm{M}$ respectively) on MDA-MB-231 cell lines. Eventually, both free PNG and PN have been shown undetectable $\mathrm{IC}_{50}$ upon MCF7 and MDA-MB-231 cancer cell lines. 


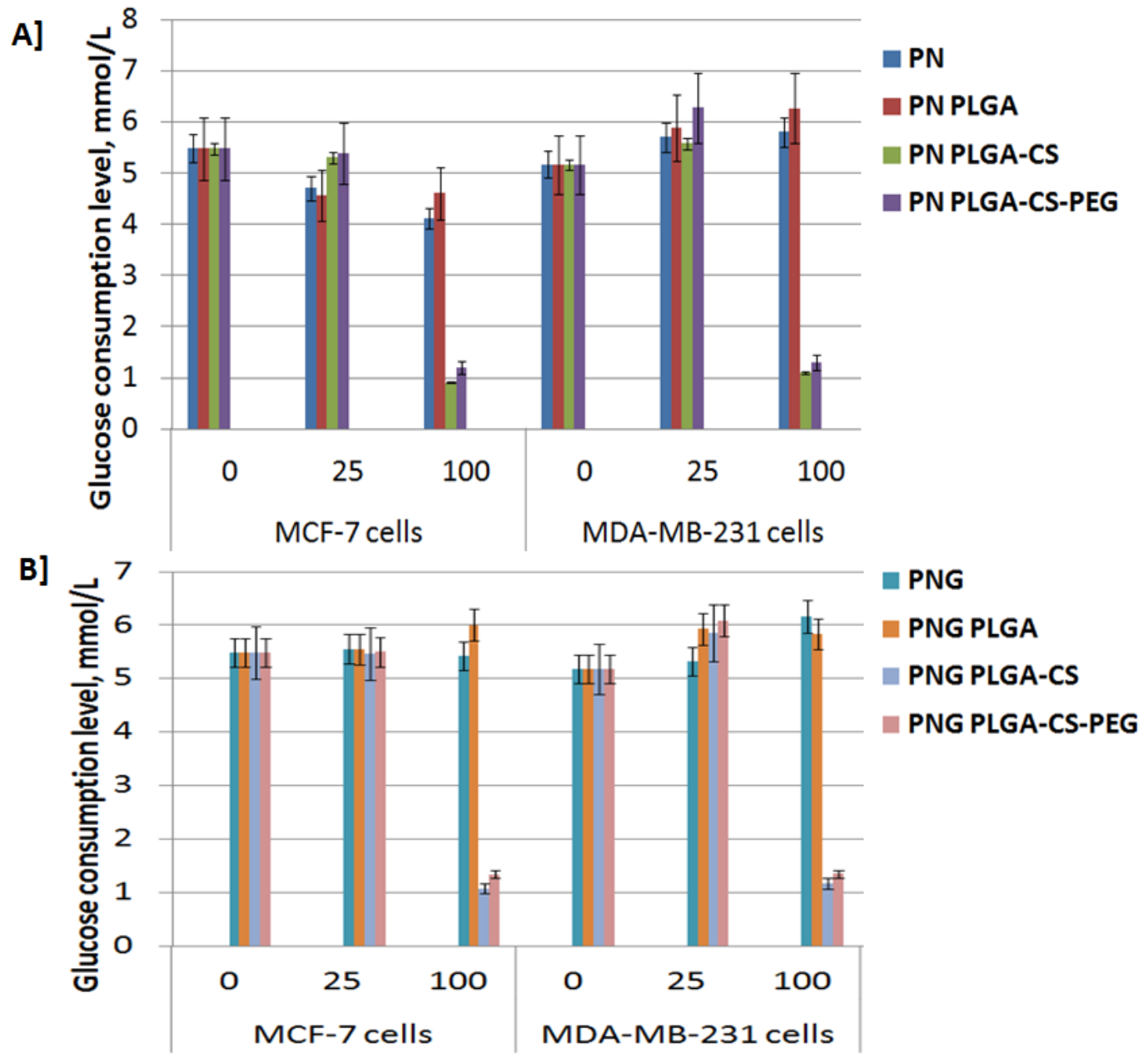

Figure 5. Glucose Consumption Levels in Breast Cancer MCF7 and MDA-MB-231 Cell Lines Using PN Prototypes (A) and PNG Prototypes (B). Three independent runs $(n=3)$ were done and illustrated.

\section{Apoptosis of $P N$ and $P N G$ prototypes}

To quantify the apoptosis induced by $\mathrm{PN}$ and $\mathrm{PNG}$ prototypes in cancerous MDA-MB-231 and MCF7 cells. We analyzed the cells by flow cytometry after Annexin V/ PI staining. As revealed in Figure 4 and Table 4, the early apoptosis rate (positive Annexin V/negative PI) of the MCF7 cells significantly increased after $24 \mathrm{~h}$ incubation of PN and PNG prototypes (PN, PN PLGACS-PEG, PNG, and PNG PLGA-CS-PEG) from 0.66\% in vehicle control to $(19.4 \%, 31.4 \%, 37.1 \%$ and $50.2 \%$, respectively), as shown in (Table 4 ). In addition, the PNloaded PLGA-CS-PEG and PNG-loaded PLGA-CS-PEG treatments caused significant increase in early apoptosis rate (positive Annexin V/negative PI) of the MDA-

Table 4. Apoptotic (Annexin V/PI) Response towards PN and PNG Prototypes against Breast Cancer MCF7 and MDA-MB-231 Cell Line

\begin{tabular}{lcccc}
\hline Apoptosis & $\begin{array}{c}\text { Ann(-)PI(-) } \\
\text { Healthy population }\end{array}$ & $\begin{array}{c}\text { Ann(+)PI(-) } \\
\text { Early apoptosis }\end{array}$ & $\begin{array}{c}\text { Ann(-)PI(+) } \\
\text { Necrosis }\end{array}$ & $\begin{array}{c}\text { Ann(+)PI(+) } \\
\text { Late apoptosis }\end{array}$ \\
\hline MCF7 cell line & & & & \\
$\quad$ Control & $99.1 \pm 4.96$ & $0.66 \pm 0.03$ & $0.18 \pm 0.01$ & $0.033 \pm 0.00$ \\
PN & $80.1 \pm 4.01$ & $19.4 \pm 0.97$ & $0.21 \pm 0.01$ & $0.34 \pm 0.02$ \\
PN PLGA-CS-PEG & $61.0 \pm 3.05$ & $31.4 \pm 1.57$ & $1.56 \pm 0.08$ & $6.00 \pm 0.30$ \\
PNG & $60.7 \pm 3.04$ & $37.1 \pm 1.86$ & $0.24 \pm 0.01$ & $1.91 \pm 0.10$ \\
PNG PLGA-CS-PEG & $48.5 \pm 2.43$ & $50.2 \pm 2.51$ & $0.14 \pm 0.01$ & $1.16 \pm 0.06$ \\
MDA-MB-231 cell line & & & & $0.76 \pm 0.04$ \\
Control & $96.5 \pm 4.83$ & $3.05 \pm 0.15$ & $0.35 \pm 0.02$ & $0.44 \pm 0.02$ \\
PN & $73.5 \pm 3.68$ & $25.8 \pm 1.29$ & $0.23 \pm 0.01$ & $0.75 \pm 0.04$ \\
PN PLGA-CS-PEG & $52.9 \pm 2.65$ & $0.12 \pm 0.01$ & $46.2 \pm 2.31$ & $38.8 \pm 1.94$ \\
PNG & $60.6 \pm 3.03$ & $0.43 \pm 0.02$ & $0.19 \pm 0.01$ & $56.9 \pm 2.85$ \\
PNG PLGA-CS-PEG & $40.6 \pm 2.03$ & $56.9 \pm 2.85$ & $0.27 \pm 0.01$ & \\
\hline
\end{tabular}



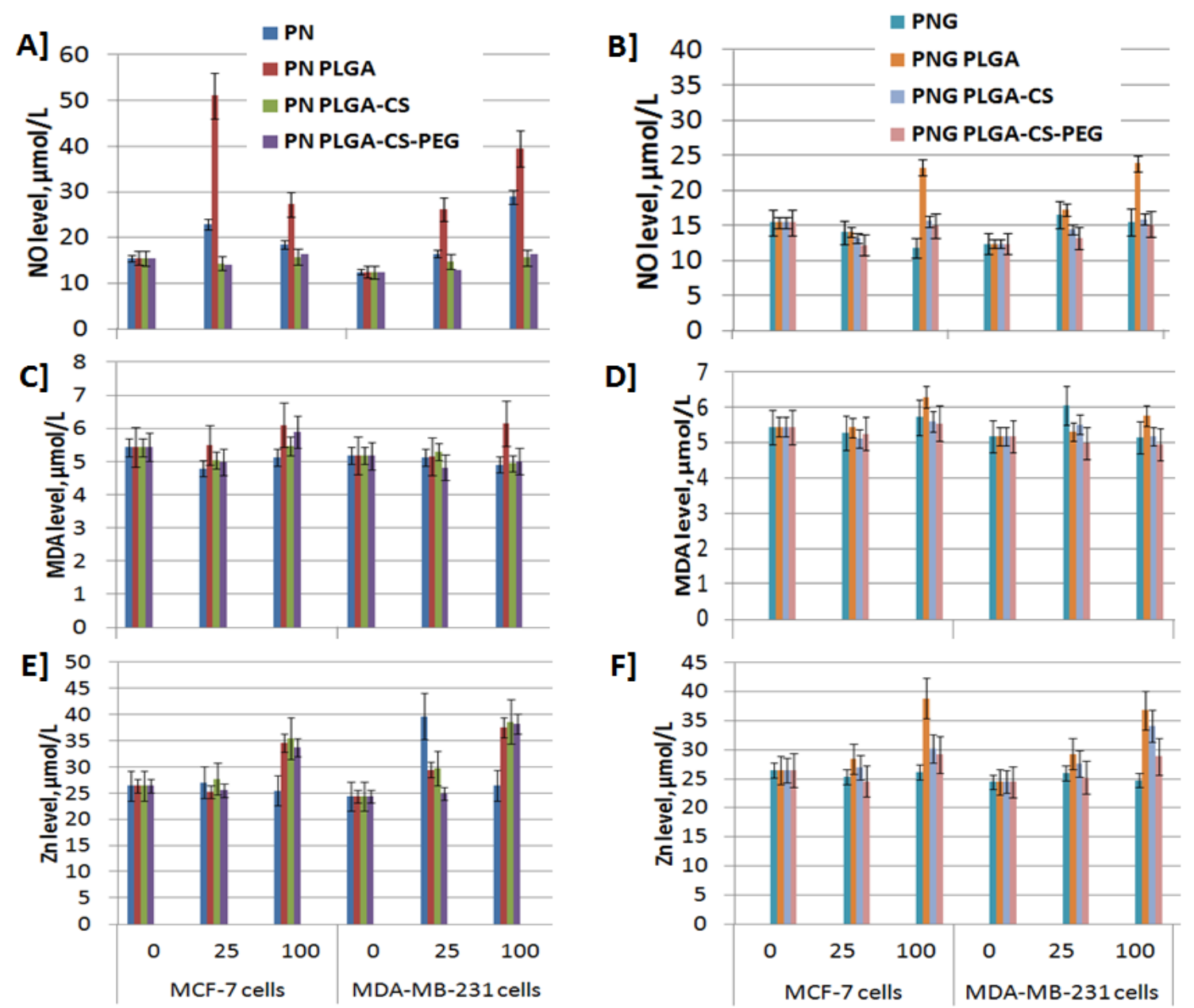

Figure 6. Stress Markers Measurement. NO levels over breast cancer MDA-MB-231 and MCF7 cell lines upon PN (A) and PNG (B) prototypes were measured. MDA levels over breast cancer MDA-MB-231 and MCF7 cell lines upon PN (C) and PNG (D) prototypes were measured. Zn levels over breast cancer MDA-MB-231 and MCF7 cell lines upon PN (E) and PNG (F) prototypes were measured. Three independent runs $(n=3)$ were done and illustrated.

MB-231 cells from $3.05 \%$ in vehicle control to $(25.8 \%$ and $56.9 \%$, respectively). PN-loaded PLGA-CS-PEG treatment tackled breast MDA-MB-231 cells through late apoptosis, while the free form of PNG treatment induced late apoptosis (positive Annexin V/positive PI) and necrosis (negative Annexin V/positive PI) in breast MDAMB-231 cells from 0.76 percent in the vehicle control to 38.8 percent, as demonstrated in (Figure 4 and Table 4).

\section{Glycolytic inhibition causes a little obstruction of glucose absorption}

Figure 5 shows the glucose consumption rate of the breast cancerous cells after $24 \mathrm{hrs}$ of incubation with the proposed nano-prototypes compared to the control. The glucose uptake by the breast cancerous cells increased significantly through $24 \mathrm{hrs}$. As a result, the glucose levels in the medium over the cancer cells have significantly decreased $(\mathrm{P}<0.01)$. The transporters were then slightly inhibited using PN and PNG nano-prototypes and the free treatments, resulting in a decrease in glucose passage ability and, as a result, a decrease in glucose consumption rate from the media into the cancer cells over a $24 \mathrm{hrs}$ drug incubation period, resulting in higher glucose levels in the media compared to the control.

\section{Stress homeostasis upon treatments}

Figs. 6A-D showed the reactive oxygen species (NO and MDA) in breast cancerous MCF7 and MDA-MB-231 cell lines upon PN and PNG prototypes. Nitric oxide (NO) levels produced by breast cancerous cells after treatments versus control; this oxidative marker was considerably elevated $(\mathrm{P}<0.05)$ after the application of PN and PNG nano-prototypes compared to the control.

$P N$ and $P N G$ prototypes interact with Zn to kill cancer cells

Figure 6E,F showed that there was an interaction between prototypes and tracking labeled nanoparticles with $\mathrm{Zn}$, where $\mathrm{Zn}$ levels were significantly increased upon PN and PNG prototypes in the tested cancer cell lines with different ratios. This represents that PN and PNG prototypes interact with $\mathrm{Zn}$ to destroy breast cancerous cells, however the precise method of action is unknown at this time.

PNG prototypes interact with genetic and protein expressions

Figures 7 and 8 illustrate the influence of treatment with PNG nanoformulations on BCL-2, BAX, Caspase 

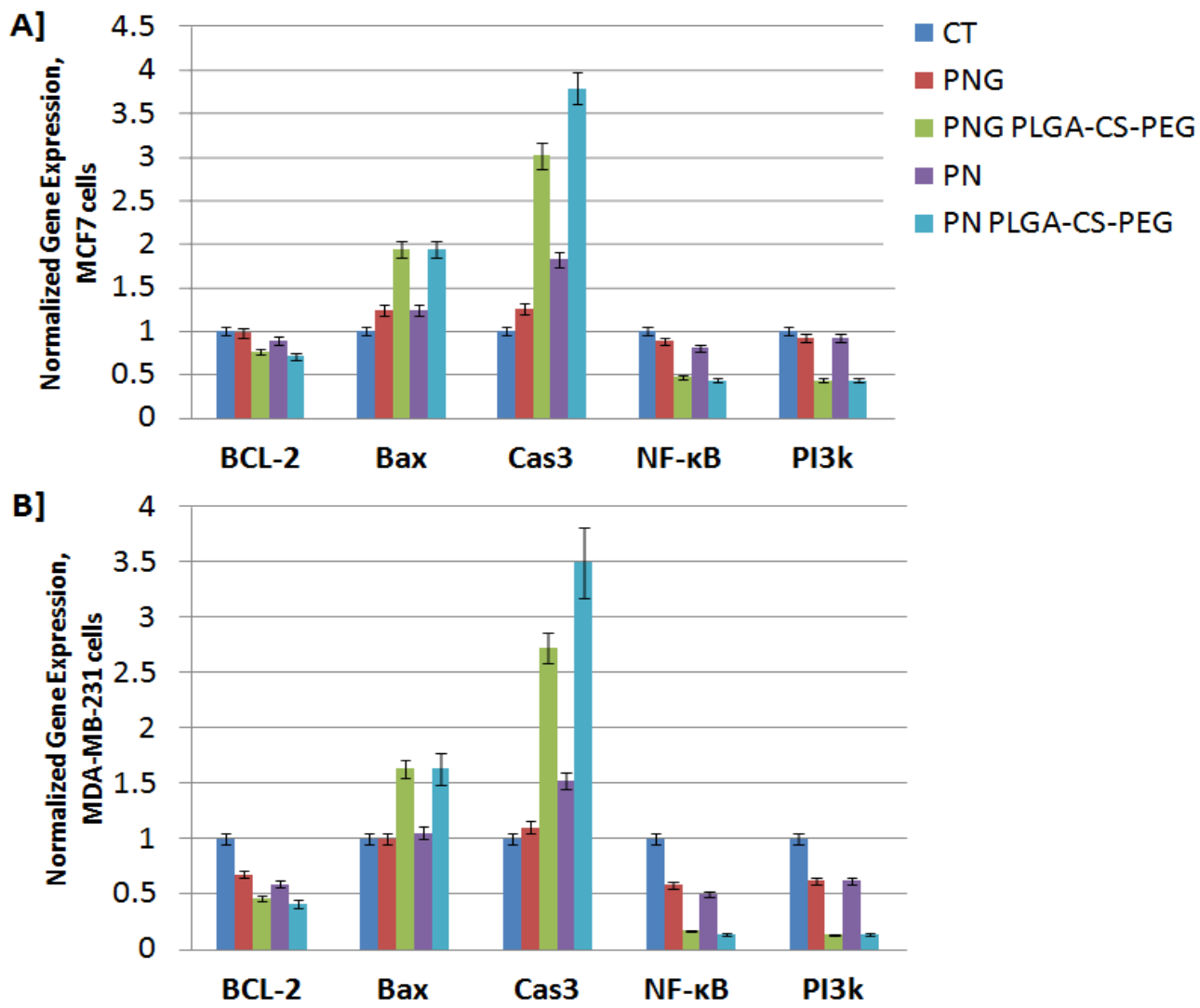

Figure 7. Genetic Profile Using Real Time qRT-PCR of BCL-2, Bax, Cas3, NF-k $\beta$ and PI3k in Breast Cancer MCF7 (A) and MDA-MB-231 (B) Cell Lines Upon Free and Nano PNG and PN Regimens. The IC $_{50}$ dosages were used and incubated for $24 \mathrm{~h}$.

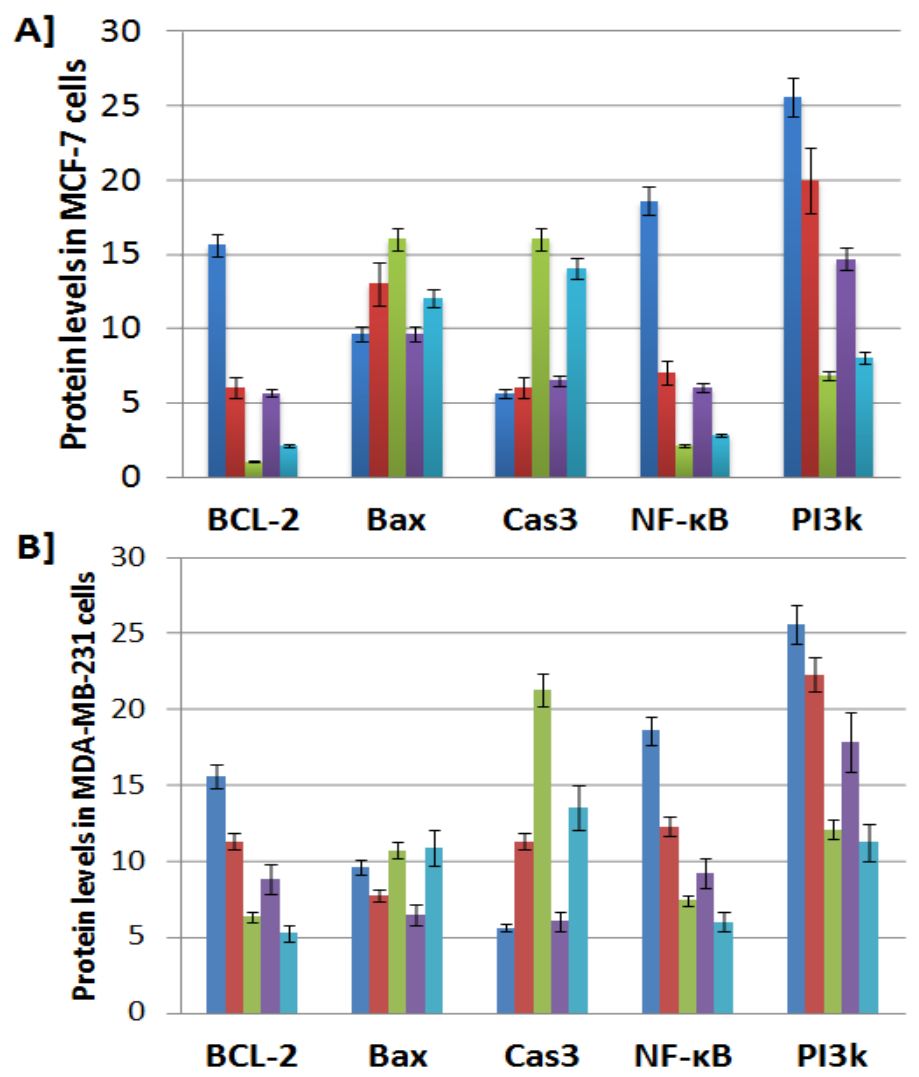

Figure 8. Protein Concentrations Using ELISA of BCL-2, Bax, Cas3, NF-k $\beta$ and PI3k in Breast Cancer MCF7 (A) and MDA-MB-231 (B) Cell Lines Upon Free and Nano PNG and PN Regimens. The $\mathrm{IC}_{50}$ dosages were used and incubated for $24 \mathrm{~h}$. 
3 (Cas3), NF- $\mathrm{kB}$ and PI3k gene (Figure 7) expression levels as well as their protein levels (Figure 8) in breast cancer MCF7 and MDA-MB-231 cell lines. There was marked down-regulation in the expression BCL-2, $\mathrm{NF}-\mathrm{KB}$ and PI3k genes in addition to their protein levels in both breast cancer cell lines upon treatment with the PNG nanoformulations when comparing with the cells treated by PNG in molecular size. On the other hand, PNG nanoformulations showed fabulous amplification in the expression level of both apoptotic markers BAX and Cas 3 on the gene and protein levels in both types of breast cancer cell lines with treatment with PNG nanoformulations when comparing with the cells treated with PNG in molecular size.

\section{Discussion}

Cancer is a global burden health globally, especially WHO recorded elevated malignancy incidences that can cause life-threatening with high financial costs for patients and countries (The International Agency for Research on Cancer, 2018). In many circumstances cancer resistance is commonly observed in cancer patients. Therefore, there is an urgent need to detect suitable anticancer therapies from natural products that are highly precise with minimal side effects (Padinjarathil et al., 2018). In our study, we used 5-flurouracil (FU) as a reference drug against several cancers such as breast, colon, and bladder (Psurski et al., 2019). There are limitations in its usage due to serious side effects, especially in some patients' genotypes (Renu et al., 2018). Indeed, new generation platforms may enhance the efficacy of the chemotherapy using nanoparticles baseddrug delivery to enhance bio-availability, solubility, and bio-compatibility (Marcazzan et al., 2018).

From such nanoparticles based-drug delivery systems, PLGA particulate have been widely used for improving sustained release, localized release, and stabilization (Wu and $\mathrm{Mu}, 2020)$. Also, chitosan was nominated to cover PLGA NPs in the current work, due to its cationic charge, bio-degradability. Thus, it enhanced the penetrating potential of the used drugs (FU, PN, PNG) across cell surfaces, inducing cytotoxicity against MCF7 and MDAMB-231 cell lines, which in agreement with a previous study (Pathomthongtaweechai and Muanprasat, 2021). In addition, PEG was added to prepare PEG-based NPs as reported in a previous publication (Zhang et al., 2017). In our study, we have synthesized new platforms of FU, PN, and PNG-loaded PLGA-CS-PEG and accomplished their self-assembly into spherical NPs, which might be used to deliver hydrophobic medicines (FU, PN, and PNG) to breast malignant cells quickly.

Previously, it was suggested that the PEGylation of PLGA NPs was demonstrated to not only reduce clearance of the loaded medication, but also to improve cancer targetability by extending plasma circulation time. In our study, the encapsulation efficiency (EE\%) of the PEGylated PLGA NPs had no significant difference with PLGA NPs in both PN and PNG encapsulation (Scheeren et al., 2016).

The resulting NPs were characterised in terms of particle size, PDI, and zeta potential, with particle sizes in the nano-range and low PDI $(\leq 0.32)$ for all nano-preparations. In terms of PDI and zeta potential, a PDI value of $(\leq 0.32)$ was found a rather narrow particle size distribution, while values of zeta potential were found to be $(1.4,1.09,-2.62$ and 0.663$) \mathrm{mV}$ for PN, PNG, FU and $(3.97,8.57,-2.37$ and 1.3$) \mathrm{mV}$ respectively for $\mathrm{PN}$, PNG and FU, respectively. We may explained this increase in positively charged zeta potential by the amine group in the CS structure suggesting an effective CS coating over PLGA NPs surface (Lu et al., 2019).

In this study, we assessed the apoptotic impact of PN and PNG nano-prototypes on breast cancer cell lines. Apoptosis is thought to be a harmonized and frequently energy-dependent process that requires the activation of a set of cysteine proteases known as "caspases" and a complicated chain of events that connect the beginning stimulus to cell necrosis (Ismail et al., 2019). The cells undergoing apoptosis exhibit caspase 3 , for example as we seen in our study (Cheng et al., 2016). Caspase- 3 is the most significant of the executioner caspases, and it is activated by mitochondrial cytochrome c release and caspase-9 action, both in dependent and independent manners (Almarzoug et al., 2020).

By expressing anti-apoptotic proteins like BCL-2 or down-regulating pro-apoptotic proteins like Bax, cancer cells can develop resistance to apoptosis. Thus, our synthesized PN and PNG PLGA-CS-PEG regimen acted as powerful tumoricidal agents induced elevation the caspase- 3 gene and protein expression levels as well as enhancement the Bax/BCL-2 ratio, in parallel with what mentioned previously in (Curti et al., 2017).

The ubiquitous transcription factor, nuclear factor kappa-B (NF- $\mathrm{B})$, regulates the expression of several genes involved in apoptosis of cancer. Any change in $\mathrm{NF}-\kappa \mathrm{B}$ gene may cause imbalance in the hemostasis, diseases, and cancer (Peng et al., 2020). NF- $\kappa$ B signaling directly induced the $\mathrm{Bcl}-2$ expression to suppress apoptosis and promote cell survival (Li et al., 2021), while NF-kB activation blocked caspase 3 and 8 cleavage, signifying that NF-kB conquers the initial signals of the cascade of caspases (Tummers and Green, 2017). In addition, The phosphatidylinositol 3-kinase (PI3K) pathway is a major survival pathway associated with cancer, and it works through a variety of mechanisms, including activating the p65 part of NF- $\kappa B$, regulatory some apoptotic candidates; for examples, BCL-2 family proteins and caspases (Liu et al., 2020).

Moreover, the accumulation of excessive reactive oxygen species (ROS) leads to oxidative DNA damage (Aggarwal et al., 2019), followed by disruption of the mitochondrial membrane potential (MMP) and release of cytochrome $\mathrm{c}$ into the cytosol, which activates caspase-9 and recruits the caspases that lead to cell apoptosis (Gupta et al., 2017). On the base of these previous mechanisms, our study came in parallel with these observations and we now can explain our results of ROS-mediated apoptotic induction through up-regulation of Bax and Cas-3 expression levels, and down-regulation of BCL-2, NF$\mathrm{KB}$ and PI3k expression levels upon treatment of MCF7 and MDA-MB-231 breast cancerous cells using PN and PNG nano-regimens.

Asian Pacific Journal of Cancer Prevention, Vol 23 
Juan's team (2021) reported that the accumulation of ROS may change the intracellular environment and disrupt the mitochondrial membrane permeability, which is associated with the intrinsic apoptosis. ROS are mainly generated in cancer cells and led to DNA damage and cell apoptosis because the cells are under much oxidative stress (Deng et al., 2017). Thus, we deduced that the primary signal of induction of apoptosis upon PN and PNG nano-regimens treatment is ROS (mainly nitric oxide in our study).

The Warburg effect, in which the rate of glucose uptake is greatly increased and a high rate of glycolysis and lactic acid generation occurs even when oxygen is present (aerobic lactatogenesis), is one of the molecular hallmarks of cancer. As a result, oncogenes have been proposed for the facilitative glucose transporter-1 (GLUT1) and monocarboxylate transporter-1 (MCT1), which are the primary glucose and lactate transporters in cancer cells, respectively (Martel et al., 2016). Mutated k-ras also boosted the expression of the GLUT1 glucose transporter in tumour cells, resulting in greater glucose uptake and increased glycolysis to produce significant quantities of energy (Abd-Rabou et al., 2018). Polyphenols impede both glucose and lactate cellular uptake by breast cancer cells, making them particularly relevant in terms of chemoprevention because they deprive breast cancer cells of their two most critical energy sources (Martel et al., 2016; Abd-Rabou et al., 2018). As a result, polyphenols' antimetabolic activity should be considered a mechanism of action that contributes to their chemopreventive potential in connection to breast cancer. The previous studies are agreed with our results in explaining the depletion in glucose level using PN and PNG nano-prototypes. This could result in the inhibition of the GLUT1 glucose transporter, a decrease in glycolysis, and the induction of apoptosis.

Zinc is a trace mineral which is vital for the functioning of many cellular processes, such as cancer etiology and outcome (Costello and Franklin et al., 2017). The polyphenols have been considered as metal chelation due to occurrence of catechol rings and some degree of hydroxylation. Sreenivasulu et al. (2010) reported that polyphenols enhance zinc uptake and metallthionein (MT) expression in caco-2 cells. MT expression accompanies/ produces changes in intracellular and extracellular zinc trafficking (Davis and Cousins, 2000). Zinc homeostasis and p53 activity appear to be critical for subsequent physiological processes such as DNA repair and ROSinduced apoptosis (Hossain et al., 2021). In addition, Zinc deficiency promotes intracellular acidosis, increases the formation of reactive oxygen species (ROS), and stimulates apoptosis in cancer cells through induction of caspases ( $\mathrm{Li}$ et al., 2020). This outcome backs up our findings, which show a link between PN, PNG, and zinc. According to our findings, the excess zinc released following the delivery of nano-prototypes may cause cell death.

In conclusion, this study offers clear documentations on the therapeutic ability of the punicalagin (PNG) and punicalin (PN) nano-prototypes of PLGA, PLGA functionalized CS, and PLGA decorated with CS and
PEG nano-prototypes in tackling breast cancer cell lines. Those nano-formulations may provide their anti-cancer activities through cytotoxicity, apoptosis, oxidative stress generation and elevation of zinc intracellular level in both breast cancerous MCF7 and MDA-MB-231 cell lines. The outcomes of the present study encourage the continuous preclinical studies for using of PGN and PN nano-prototypes as a nano-based natural pharmacological therapy against breast cancer in-vitro and in-vivo.

\section{Author Contribution Statement}

All authors have contributed in this work and approved the final manuscript version.

\section{Acknowledgements}

We would like to acknowledge National Research Center for providing the project's fund (ID: 11010334).

This paper is extracted from an internal project of the National Research Center (Research Plan 11).

\section{Ethical Approval}

This project was ethically approved (ID: 16/335) from the Medical Research and Clinical studies institute of the National Research Center, Egypt.

Availability of data

Available after authors' approval.

\section{Conflict of interest}

The authors declare that there is no conflict of interest.

\section{References}

Abdelaziz AH, Shawki MA, Shaaban AM, et al (2021). Breast cancer awareness among Egyptian women and the impact of caring for patients with breast cancer on family caregivers' knowledge and behaviour. Res Oncol, 17, 1-8.

Abd-Rabou AA, Ahmed HH (2017). CS-PEG decorated PLGA nano-prototype for delivery of bioactive compounds: A novel approach for induction of apoptosis in HepG2 cell line. $A d v$ Med Sci, 62, 357-67.

Abd-Rabou AA, Shalby AB, Ahmed H. (2018). Selenium Nanoparticles induce the chemo-sensitivity of fluorouracil nanoparticles in breast and colon cancer cells. Biol Trace Elem Res, 2018, doi: 10.1007/s12011-018-1360-8.

Abd-Rabou AA, Zoheir K, Ahmed HH (2012). Potential impact of curcumin and taurine on human hepatoma cells using huh-7 cell line. Clin Biochem, 45, 1519-21.

Aggarwal V, Tuli HS, Varol A, et al (2019). Role of reactive oxygen species in cancer progression: Molecular Mechanisms and Recent Advancements. Biomolecules, 9, 735.

Ahmed HH, Abd-Rabou AA, Hassan AZ, Kotob SE (2015). Phytochemical analysis and anti-cancer investigation of Bswellia serrata Bioactive Constituents in vitro. Asian Pac J Cancer Prev, 16, 7179-88.

Almarzoug MHA, Ali D, Alarifi S, Alkahtani S, Alhadheq AM. (2020). Platinum nanoparticles induced genotoxicity and apoptotic activity in human normal and cancer hepatic cells via oxidative stress-mediated Bax/Bcl-2 and caspase- 3 expression. Environ Toxicol, 35, 930-941.

Berköz M, Krośniak M (2020). Punicalagin induces apoptosis 
in A549 cell line through mitochondria-mediated pathway. Gen Physiol Biophys, 39, 557-67.

Cheng HY, Tian DM, Tang JS, Shen WZ, Yao XS (2016). Cardiac glycosides from the seeds of Thevetia peruviana and their pro-apoptotic activity toward cancer cells. J Asian Nat Prod Res, 18, 837-47.

Costello LC, Franklin RB (2017). Decreased zinc in the development and progression of malignancy: an important common relationship and potential for prevention and treatment of carcinomas. Expert Opin Ther Targets, 21, 51-66.

Curti V, Di Lorenzo A, Dacrema M, et al (2017). In vitro polyphenol effects on apoptosis: An update of literature data. Semin Cancer Biol, 46, 119-31.

Das IP, Stevens L, Muha C, Sivaram S, Kostelecky B (2019). Integration of research priorities in low and middle-income countries: A Qualitative Analysis of National Cancer Control Plans. J Cancer Policy, 20, 100190.

Davis SR, Cousins RJ (2000). Metallothionein expression in animals: A physiological perspective on function. $J$ Nutr, 130, 108518.

De Miguel D, Gallego-Lleyda A, Ayuso JM, et al (2016).TRAILcoated lipid-nanoparticles overcome resistance to soluble recombinant TRAIL in non-small cell lung cancer cells. Nanotechnology, 27, 185101.

Deng Y, Li Y, Yang F, et al (2017). The extract from Punicagranatum (pomegranate) peel induces apoptosis and impairs metastasis in prostate cancer cells. Biomed Pharmacother, 93, 976-84.

Gosset-Erard C, Zhao M, Lordel-Madeleine S, Ennahar S (2021). Identification of punicalagin as the bioactive compound behind the antimicrobial activity of pomegranate (Punica granatum L.) peels. Food Chem, 352, 129396.

Gupta A, Singh AK, Kumar R, et al (2019). Corilagin in Cancer: A Critical Evaluation of Anticancer Activities and Molecular Mechanisms. Molecules, 24, 3399.

Gupta E, Kaushik S, Purwar S, et al (2017). Anticancer potential of steviol in MCF-7 human breast cancer cells. Pharmacogn Mag, 13, 345-50.

Hossain KFB, Hosokawa T, Saito T, Kurasaki M (2021). Zinc-pretreatment triggers glutathione and Nrf2-mediated protection against inorganic mercury-induced cytotoxicity and intrinsic apoptosis in PC12 cells. Ecotoxicol Environ Saf, 207, 111320.

Ismail NI, Othman I, Abas F, H Lajis N, Naidu R (2019). Mechanism of apoptosis induced by curcumin in colorectal cancer. Int J Mol Sci, 20, pii: E2454.

Juan CA, Pérez de la Lastra JM, Plou FJ, Pérez-Lebeña E (2021). The Chemistry of Reactive Oxygen Species (ROS) Revisited: Outlining Their Role in Biological Macromolecules (DNA, Lipids and Proteins) and Induced Pathologies. Int $J \mathrm{Mol}$ Sci, 22, 4642.

Khan AA, Alanazi AM, Alsaif N, Wani TA, Bhat MA (2021). Pomegranate peel induced biogenic synthesis of silver nanoparticles and their multifaceted potential against intracellular pathogen and cancer. Saudi J Biol Sci, 28, 4191-4200.

Li Y, Qiao Y, Wang H, Wang Z (2021). Intraperitoneal injection of PDTC on the NF-kB signaling pathway and osteogenesis indexes of young adult rats with anterior palatal suture expansion model. PLoS One, 16, e0243108.

Liu R, Chen Y, Liu G, et al (2020). PI3K/AKT pathway as a key link modulates the multidrug resistance of cancers. Cell Death Dis, 11, 797.

Lombardo D, Kiselev MA, Caccamo MT (2019). Smart nanoparticles for drug delivery application: Development of Versatile Nanocarrier Platforms in Biotechnology and
Nanomedicine. J Nanomaterials, 2019, 1-27.

Lu B, Lv X, Le Y (2019): Chitosan-modified PLGA nanoparticles for control-released drug delivery. Polymers (Basel), 11, 304.

Macierzyński J, Sójka M, Kosmala M, Karlińska E (2020). Transformation of oligomeric ellagitannins, typical for rubus and fragaria genus, during strong acid hydrolysis. J Agric Food Chem, 68, 8212-22.

Marcazzan S, Varoni EM, Blanco E, Lodi G, Ferrari M (2018). Nanomedicine, an emerging therapeutic strategy for oral cancer therapy. Oral Oncol, 76, 1-7.

Martel F, Guedes M, Keating E (2016). Effect of polyphenols on glucose and lactate transport by breast cancer cells. Breast Cancer Res Treat, 157, 1-11.

Miller KD, Fidler-Benaoudia M, Keegan TH, et al (2020). Cancer statistics for adolescents and young adults, 2020. CA Cancer J Clin, 70, 443-59.

Naeem GA, Muslim RF, Rabeea MA, Owaid MN, Abd-Alghafour NM. (2020). Punica granatum L. mesocarp-assisted rapid fabrication of gold nanoparticles and characterization of nano-crystals. Environ Nanotechnol Monitoring Manage, 14, 100390.

Padinjarathil H, Joseph MM, Unnikrishnan BS, et al (2018). Galactomannan endowed biogenic silver nanoparticles exposed enhanced cancer cytotoxicity with excellent biocompatibility. Int J BiolMacromol, 118, 1174-82.

Parveen S, Sahoo SK (2011). Long circulating chitosan/PEG blended PLGA nanoparticle for tumor drug delivery. Eur $J$ Pharmacol, 670, 372-83.

Pathomthongtaweechai N, Muanprasat C (2021). Potential applications of chitosan-based nanomaterials to surpass the gastrointestinal physiological obstacles and enhance the intestinal drug absorption. Pharmaceutics, 13, 887.

Peng C, Ouyang Y, Lu N, Li N (2020). The NF-кB signaling pathway, the microbiota, and gastrointestinal tumorigenesis: Recent Advances. Front Immunol, 11, 1387.

Psurski M, Filip-Psurska B, Cuprych M, Wietrzyk J, Oleksyszyn J (2019). 3,4-dimethoxybenzyl isothiocyanate enhances doxorubicin efficacy in LoVoDX doxorubicin-resistant colon cancer and attenuates its toxicity in vivo. Life Sci, pii: S0024-3205(19)30442-4. doi: 10.1016/j.lfs.2019.06.005.

Rai R, Alwani S, Badea I (2019). Polymeric nanoparticles in gene therapy: New Avenues of Design and Optimization for Delivery Applications. Polymers (Basel), 11, pii: E745.

Renu K, V G A, P B TP, Arunachalam S (2018). Molecular mechanism of doxorubicin-induced cardiomyopathy - An update. Eur J Pharmacol, 818, 241-53.

Sahm BDB, Peres J, Rezende-Teixeira P, et al (2020). Targeting the oncogenic TBX2 transcription factor with chromomycins. Front Chem, https://doi.org/10.3389/fchem.2020.00110.

Scheeren LE, Nogueira DR, Macedo LB, et al (2016). PEGylated and poloxamer-modified chitosan nanoparticles incorporating a lysine-based surfactant for $\mathrm{pH}$-triggered doxorubicin release. Colloids Surf B Biointerfaces, 138, 117-27.

Seeram N, Lee R, Hardy M, Heber D (2005). Rapid large scale purification of ellagitannins from pomegranate husk, a by-product of the commercial juice industry. Sep Purif Technol, 41, 49-55.

Shalby AB, Abd-Rabou AA, Ahmed HH (2017). Nano-Se crosstalks with nano-DOX/FU to selectively hack hepatic cancer cells and spare normal cells healthy: A mechanismbased study. J Appl Pharm Sci, 7, 3-12.

Shende P, Mallick C (2020). Nanonutraceuticals: A way towards modern therapeutics in healthcare. J Drug Delivery Sci Technol, 58, 101838.

Silacci P, Tretola M (2019). Pomegranate's Ellagitannins: Metabolism and Mechanisms of Health Promoting 
Ahmed A. Abd-Rabou et al

Properties. Nutr Food Sci Int J, 9, DOI: 10.19080/ NFSIJ.2019.09.555766.

Sreenivasulu K, Raghu P, Nair KM (2010). Polyphenol-rich beverages enhance zinc uptake and metallothionein expression in Caco-2 cells. J Food Sci, 75, H123-8. doi: 10.1111/j.1750-3841.2010.01582.x.

Tummers B, Green DR (2017). Caspase-8: regulating life and death. Immunol Rev, 277, 76-89.

Van Meerloo J, Kaspers GJ, Cloos J (2011). Cell sensitivity assays: the MTT assay. Methods Mol Biol, 731, 237-45.

Vishnoi K, Viswakarma N, Rana A, Rana B (2020). Transcription factors in cancer development and therapy. Cancers (Basel), 12, 2296.

Wu C, Mu H (2020). Lipid and PLGA microparticles for sustained delivery of protein and peptide drugs. Pharm Nanotechnol, 8, 22-32.

Yang C, Zhang ZC, Liu TB, et al (2020). E2F1/2/7/8 as independent indicators of survival in patients with cervical squamous cell carcinoma. Cancer Cell Int, 20, 500.

Zhang L, Zhou Y, Shi G, Sang X, Ni C (2017). Preparations of hyperbranched polymer nano micelles and the $\mathrm{pH} /$ redox controlled drug release behaviors. Mater SciEng C Mater Biol Appl, 79, 116-22.

\section{c) (i) (8)}

This work is licensed under a Creative Commons AttributionNon Commercial 4.0 International License. 